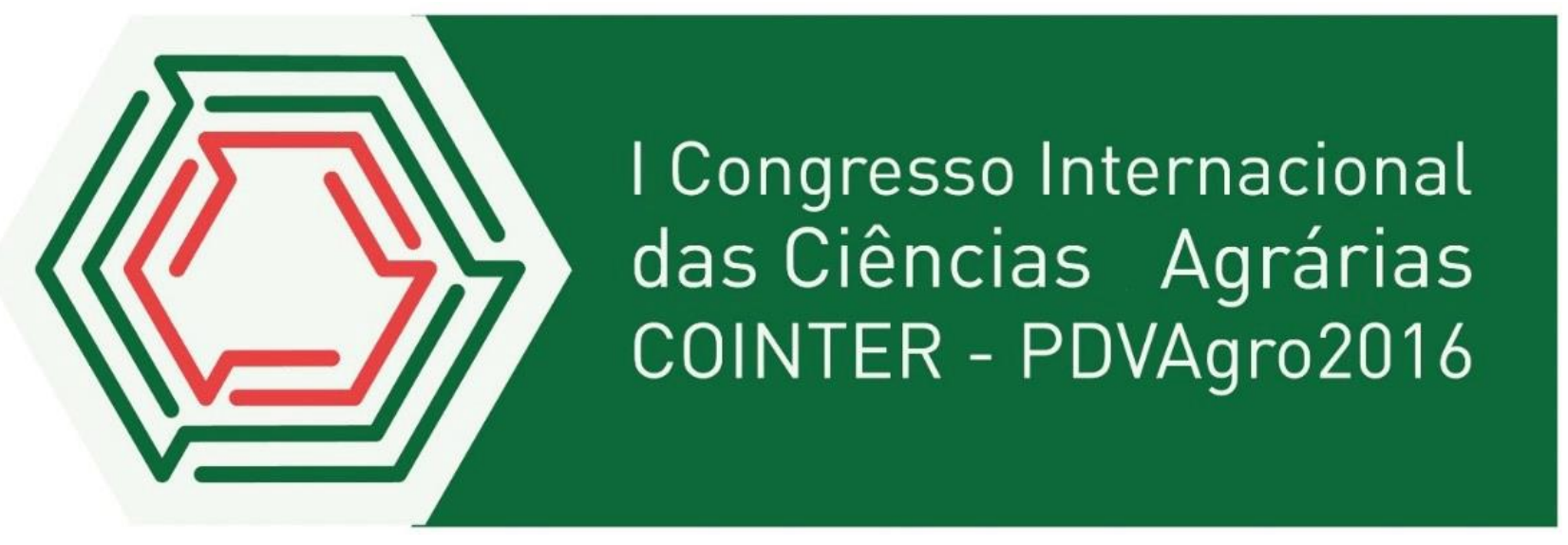

\title{
INCIDÊNCIA DE MOSCA-BRANCA (HEMIPTERA: ALEYRODIDAE) EM CULTIVOS BERINJELA NA REGIÃO DA MATA PERNAMBUCANA
}

\author{
Apresentação: Pôster
}

Anderson Ricardo Galdino da Silva ${ }^{1}$; Marcelânio Laurentino dos Santos ${ }^{2}$; Timóteo Ângelo do Nascimento ${ }^{3}$; Alisson Rocha da Silva ${ }^{4}$

\section{Introdução}

Devido ao crescente interesse da população por uma alimentação natural e saudável, com baixas calorias, com valor nutricional e de uso medicinal, o volume de comercialização da berinjela (Melongena solanum L.) vem aumentando (NODA,1980 apud FAO, 1998).

A berinjela vem sendo atacada por diversas pragas e doenças, sendo uma das principais a mosca-branca (Bemisia argentifolli). Sendo uma das pragas mais conhecidas no mundo e está presente em praticamente todas as regiões agrícolas, principalmente em regiões de clima tropical e subtropical (GODINHO, 2011). Esses insetos podem causar danos diretos, causados pela sucção da seiva, e indireto as culturas, como vetor de vários geminivírus com sintomatologia variada (MIZUNO, 1997).

Para reduzir ou minimizar o ataque da mosca-branca, o produtor pode utilizar o Manejo Integrado de Pragas (MIP), que consiste no controle de pragas com bases ecológicas que envolvem qualquer tipo de problema que limite a produção agrícola decorrente da competição interespecífica

\footnotetext{
${ }^{1}$ Agronomia, IFPE campus Vitória de Santo Antão, andersonrgs2013@gmail.com

${ }^{2}$ Agronomia, IFPE campus Vitória de Santo Antão, marcelaniolaurentino@gmail.com

${ }^{3}$ Agronomia, IFPE campus Vitória de Santo Antão, timoteo.ifpe@gmail.com

${ }^{4}$ Mestre em Agronomia, IFPE campus Vitória de Santo Antão, alisson.rocha@vitoria.ifpe.edu.br
} 
(GALLO et al, 2002).

O objetivo desse trabalho foi avaliar a ocorrência de mosca-branca no cultivo de berinjela de forma preliminar, com vistas a orientar uma posterior avaliação da flutuação populacional deste inseto considerando todas as estações do ano.

\section{Fundamentação Teórica}

Na década de 1970, houve um alarmante crescimento populacional devido à expansão da área cultiva com soja, que é um dos hospedeiros desse inseto. Recentemente apareceu um novo biótipo dessa espécie chamada de Bemisia tabaci biótipo B ou Bemisia argentifolii, que causa maiores problemas (GALLO et al, 2002).

Segundo Scarpellini, os principais danos causados pela Bemisia tabaci (especialmente pertence ao biótipo B ou B. argentifolii) são a sucção e deformação das plantas por ninfas; aparecimento de fumagina; transmissão de viroses pelas ninfas prejudicando o crescimento, debilitando e deformando as plantas.

O Manejo Integrado de Pragas - MIP surge como uma ferramenta para o controle dos insetospraga. O MIP envolve o uso simultâneo de diferentes técnicas de supressão populacional, objetivando manter os insetos em um nível populacional que não cause danos econômicos (RAMIRO, 2000) e interfira o mínimo possível no equilíbrio do ecossistema.

O monitoramento de populações é uma prática capaz de conduzir o produtor a decisões mais abalizadas sobre o comportamento dos insetos, sejam eles pragas ou inimigos naturais. $\mathrm{O}$ conhecimento das épocas de pico de infestação do inseto-praga, sua distribuição e danos à planta constituem ferramentas importantes, uma vez que norteiam as atividades do produtor sobre a ocorrência de uma determinada praga numa época, permitindo o planejamento da produção com maior confiabilidade e segurança na utilização de produtos fitossanitários específicos para o insetopraga (MALTA et al., 2000).

\section{Metodologia}

O estudo foi feito na Zona Rural do Município de Chã Grande, o qual está distante $82 \mathrm{~km}$ da capital do Estado de Pernambuco. Situado na Mesorregião da Mata Pernambucana, está a 434 m de 
altitude e na latitude $8^{\circ} 13^{\prime} 43^{\prime}$ ' S e longitude $35^{\circ} 27^{\prime} 43^{\prime}$ ' W, além de possuir clima Tropical As', segundo classificação de Köppen (IBGE).

A técnica de amostragem utilizada foi à batida de folhas em bandeja de fundo branco, sugerido por Pedigo (1988) como a técnica de amostragem mais empregada para determinar as densidades populacionais dos insetos que exploram folhas como substrato alimentar. A técnica foi executada amostrando-se a região apical da planta (ramo terminal e os ramos laterais nesta região). As folhas foram sacudidas no interior da bandeja, usando-se movimentos bruscos e vibratórios, segurando-a de forma a não afugentar os adultos. A seguir, foram contadas as moscas-brancas presentes na mesma, descartando os indivíduos mortos. Foram feitas amostragens utilizando uma bandeja de plástico branca, com dimensões de $40 \mathrm{~cm}$ de comprimento x $35 \mathrm{~cm}$ de largura x $9 \mathrm{~cm}$ de profundidade.

Para escolha das lavouras, consideraram-se as que se encontravam sob ataque e que possuíam características homogêneas quanto à topografia, tipo de solo e espaçamento (BARRIGOSSI, 1997). As plantas avaliadas localizavam-se equidistantemente ao longo e entre as linhas de plantio, de modo a cobrir toda a área plantada e eliminar tendências direcionais (MIDGARDEN e al., 1993).

Foram monitoradas semanalmente 35 lavouras diferentes, de Setembro a Outubro de 2014. Os plantios possuíam área não superior a 1 ha. Observou-se a densidade populacional da mosca branca (Bemisia tabaci biótipo B ou Bemisia argentifolli) na fase adulta na cultura da berinjela na fase reprodutiva.

Foram elaborados gráficos e tabelas de forma a obter uma análise descritiva da ocorrência de mosca-branca na lavoura de berinjela.

\section{Resultados e Discussões}

Das lavouras monitoradas, $80 \%$ apresentaram ocorrência de B. argentifolli, sendo 17 lavouras com até 5 indivíduos amostrados, 7 lavouras contendo entre 6 e 10 indivíduos, 3 lavouras contendo entre 11 e 15 indivíduos e 1 lavoura contendo acima de 15 indivíduos (Tabela 1). Foram coletados no período amostral 156 indivíduos de $B$. argentifolli.

Como a simples ocorrência de insetos vetores inspira cuidados maiores (ZUCCHI et al., 1993), a ocorrência acentuada de B. argentifolli torna-se fator limitante a produção de berinjela na região, visto que medidas de controle não baseadas em um Manejo Integrado de Pragas vêm sendo tomadas e agravando a situação de olericultores na região, elevando os custos de produção ou até 
mesmo fazendo com que produtores abandonem a cultura da berinjela.

A densidade de ataque registrada também demonstra que se faz necessária uma mudança de estratégias de controle, adotando aquelas que venham a reduzir o nível populacional deste insetopraga na cultura de berinjela. $\mathrm{O}$ aspecto mais importante a se destacar é que este trabalho identificou a necessidade de se realizar um levantamento mais abrangente de B. argentifolli na lavoura e na região, tornando possível adotarem-se medidas de controle baseadas nas características edafoclimáticas e biológicas locais, com opções acessíveis ao agricultor da região.

Tabela 1: Densidade Populacional de Moscas-brancas e datas das amostragens. Fonte: Própria.

\begin{tabular}{c|c|c|c|c|c|c|c|c}
\hline Data de Coleta & $04 / 09$ & $10 / 09$ & $18 / 09$ & $25 / 09$ & $02 / 10$ & $16 / 10$ & $23 / 10$ & $\begin{array}{c}\text { Total de } \\
\text { Insetos/área }\end{array}$ \\
\hline Sr. Sandro - 1 & 10 & 0 & 1 & 6 & 0 & 1 & 4 & 22 \\
\hline Sr. Sandro - 2 & 1 & 1 & 2 & 0 & 4 & 6 & 3 & 17 \\
\hline Sr. Bruno & 0 & 0 & 1 & 0 & 1 & 4 & 14 & 20 \\
\hline Gilvan & 4 & 0 & 7 & 3 & 8 & 15 & 25 & 62 \\
\hline Sr. Donga & 1 & 1 & 3 & 7 & 11 & 4 & 8 & 35 \\
\hline Total de Insetos & \multicolumn{1}{|l}{} & & & & & & 156 \\
\hline
\end{tabular}

\section{Conclusões}

A cultura da berinjela produzida na região da Mata Pernambucana encontra-se sob elevado ataque de Bemisia argentifolli.

Fazem-se necessários estudos mais amplos de flutuação populacional deste inseto para a construção de estratégias de controle mais eficazes do que as atualmente adotadas na região.

\section{Referências}

BARRIGOSSI, J. A. F. Development of an integrated pest management for the mexican bean beetle (Epilachna varivestis Mulsant) as a pest of dry bean (Phaseoulus vulgaris L.). Nebraska: 1997, 125p. Dissertation (Doctor of Philosophy in Entomology), University of Nebrasca, 1997. 
e Limites Territoriais. Visualizado em: 16 set 2015.

FAO. The state of the world's plant genetic resources for food and agriculture. Rome: Food and Agriculture Organization of United Nations, 1998.510p.

GODINHO, R.; TUKAMOTO, H. Mosca-branca causa perdas de produtividade e lucratividade na horticultura, feijão, algodão e soja. Pesquisa IAHARA.

GALLO, D. et al. Entomologia Agrícola, Piracicaba, FEALQ, 2002.

MALTA, A.W.O.; RODRIGUES, E.J.R.; GONÇALVES, N.P.; REIS, P.R.; SILVA, R.A.; CALIL, A.C.P. Flutuação populacional das principais pragas transmissoras de viroses no tomateiro (Lycopersicon esculentum Mill) na meso-região metropolitana de Belo Horizonte. In: CONGRESSO BRASILEIRO DE OLERICULTURA, 45., 2000 Fortaleza-CE. Anais... Ceará. 2000. Disponível em: <http://www.abhorticiencia.com.br/Biblioteca/Default.asp>. Acesso em: 18 set. 2005.

MIDGARDEN, D. G.; YOUNGMAN, R. R.; FLEISCHER, S. J. Spatial analysis of counts of western corn rootworm (Coleoptera: Chrysomelidae) adults on yellow sticky traps in corn: geostatistics and dispersion indices. Environmental Entomology, Lanham, v. 22, n. 5, p. 1124-1133, Oct. 1993.

MIZUNO, A.C.R.; VILLAS BÔAS, G.L. Biologia da mosca-branca (Bemisia argentifolii) em tomate e repolho. Embrapa Hortaliças. nº 1, dez/1997.

PEDIGO, L.P. Entomology and pest management. New York: Macmillan. 1988, 646p.

RAMIRO, Z.A. Manejo integrado da mosca-branca Bemisia argentifolii. In: REUNIÃO ITINERANTE DE FITOSSANIDADE DO INSTITUTO BIOLÓGICO, 3., 2000, Mogi das Cruzes, SP. Anais..., São Paulo: Instituto Biológico, 2000. p. 68-78.

ZUCCHI, R.A.; SILVEIRA NETO, S.; NAKANO, O. Guia de identificação de pragas agrícolas. Piracicaba: FEALQ, 1993. 139p. 